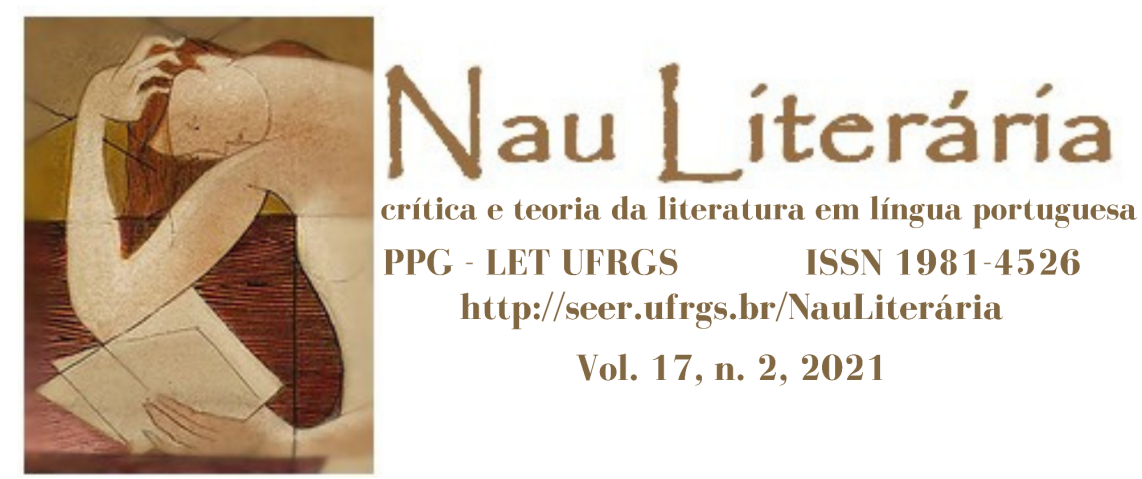

\title{
A Mensagem, de Fernando Pessoa, e o sentido do tangível
}

\section{Mensagem and the sense of the tangible}

Dionísio Vila Maior ${ }^{1}$

Resumo: Procurarei refletir sobre a Mensagem pessoana, domínio textual onde variavelmente se manifestam, e sempre se manifestarão, múltiplas virtualidades de informação estética, tendo essencialmente em conta o seu perfil de texto épico dos "tempos modernos", bem como algumas linhas temáticas centrais relacionadas com a conceção quinto-imperialista e sebastianista (consequência direta da fortuna concetual e simbólica que historicamente lhe está adscrita), a relação entre o sentimento de desalento e o sentimento de esperança, a celebração de possibilidades outras que o racionalismo positivista não soube oferecer, a abordagem poética do passado, seguindo um particular vigor patriótico de índole nacionalista e sebastianista (que, aliás, Pessoa mostra desde muito cedo), procurando, assim, compreender sentidos efetivos da narrativa sebastianista.

Palavras-Chave: Fernando Pessoa; Mensagem; Sebastianismo; Identidade; Esperança

Abstract: I tried to reflect on the Messagem of Pessoa, textual domain where variably manifest themselves, and always will, multiple virtualities of aesthetic information, taking into account its' epic text profile of "modern times", as well as some central theme lines with the fifth-imperialist and sebastianist concession (direct consequence of the conceptual and symbolic fortune that is historically assigned to it), the relationship between the feeling of discouragement and the feeling of hope, the celebration of other possibilities that the positivist rationalism couldn't offer, the approach of a particular patriotic vigor of nationalist and sebastianist nature (that, indeed, Pessoa shows from quite early), looking for, this way, to understand effective senses of the sebastianist narrative.

Keywords: Fernando Pessoa; "Mensagem"; Sebastianism; Identity; Hope

\footnotetext{
${ }^{1}$ Professor Associado com Agregação na Universidade Aberta (Portugal). Visiting Professor na Università degli Studi di Padova e na Universidade Maria Curie Sklodowska, de Lublin. Professor-Investigador da Universidade da Sorbonne (Paris IV) e Professor Convidado de diversas Universidades Brasileiras, Italianas, Francesas, Espanholas, Polacas e Peruanas.
} 


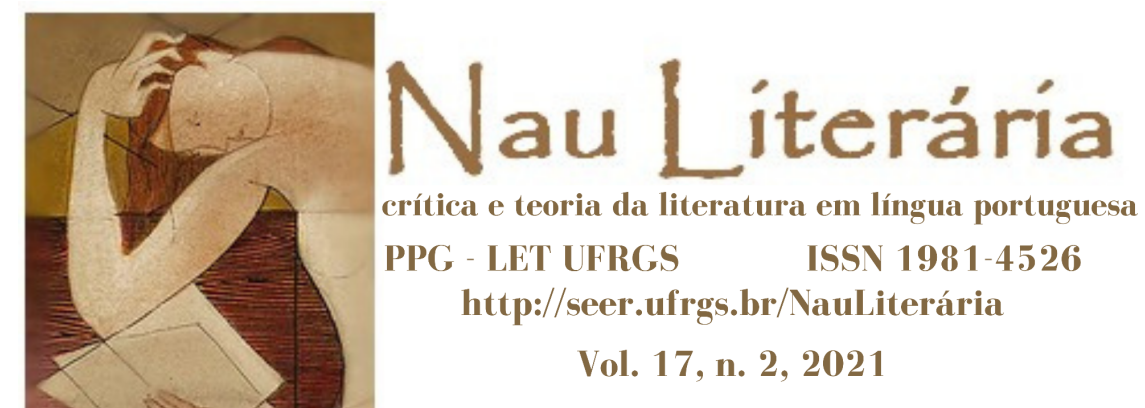

Respondendo a um inquérito promovido em 1926 por Augusto da Costa (resposta essa que foi publicada a 28 de maio e 5 de junho do mesmo ano, no Jornal do Comércio e das Colónias), e centrando-se no «mito sebastianista», declara Fernando Pessoa o seguinte:

[...] não temos que criar um mito, senão que renová-lo. Comecemos por nos embebedar desse sonho, por o integrar em nós, por o incarnar. Feito isso [...], o sonho se derramará sem esforço em tudo que dissermos ou escrevermos [...]. Então se dará na alma da Nação o fenómeno imprevisível de onde nascerão as Novas Descobertas, a Criação do Mundo Novo, o Quinto Império. Terá regressado El-Rei D. Sebastião (PESSOA, F., 1986c: 710).

Num outro texto, com a indicação "O Sebastianismo — Introdução", escreve:

[...] morto D. Sebastião, o corpo, se conseguirmos evocar qualquer cousa em nós que se assemelha à forma do esforço de D. Sebastião, ipso facto o teremos evocado e a alma dela entrará para a forma que evocámos. Por isso quando houverdes criado uma cousa cuja forma seja idêntica à do pensamento de D. Sebastião, D. Sebastião terá regressado, mas não só regressado modo dizendo, mas na sua realidade e presença concreta, posto que não fisicamente pessoal (id.: 687).

Deixando de lado o que, num outro contexto, se imporia dizer sobre as origens e o desenvolvimento histórico do mito sebastianista, ou sobre o fenómeno da metempsicose estudado por Pessoa, o que desde logo destas palavras podemos retirar é a ideia de que a presentificação daquele que permitirá o advento do «Quinto Império», desse «Mundo Novo» a que Pessoa se refere, depende de cada indivíduo, do vigor com que cada indivíduo em si integra essa ideia e de uma precisa reprodução de atributos emblemáticos do evocado. A noção, portanto, da figuração expressa do neto de D. João III e filho do jovem D. João - que falece pouco antes de o próprio filho nascer — encontrar-se-á, em primeira e última instâncias, no indivíduo ou coletividade que o evoquem, bem como na consciência e intensidade com que o fazem.

\section{Uma epopeia dos tempos modernos}

Assim se esboça uma linha temática que central mas variavelmente percorre a pensada e calculada Mensagem de Pessoa — constituída por 44 poemas escritos entre 1913 e 1934 (ano da sua publicação), e com a qual concorreu, como se sabe, ao Prémio Antero de Quental, concedido pelo Secretariado de Propagada Nacional a uma obra de natureza nacionalista, 


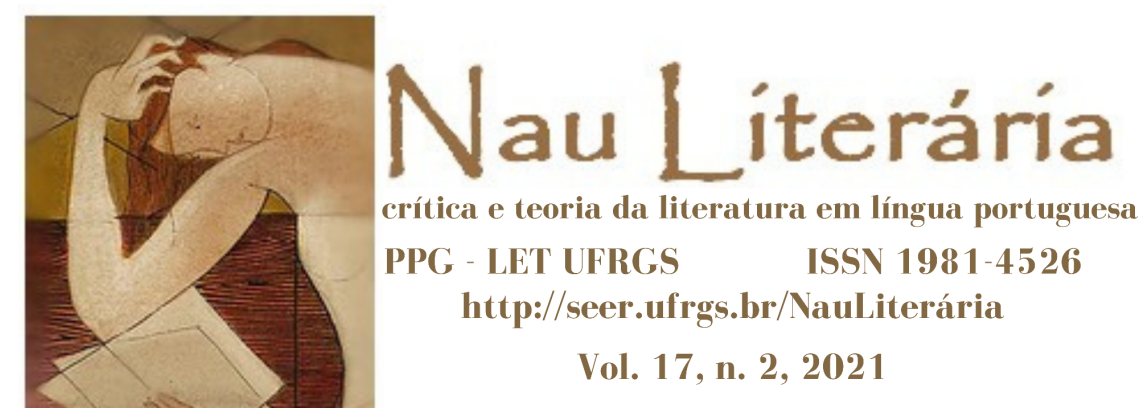

tendo aí recebido um prémio de segunda categoria (prémio de consolação, aliás, nunca por aquele reconhecido).

Ainda que se configurando como uma obra polifonicamente considerada no que à sua classificação diz respeito - ora ajustada às colorações épicas, líricas, elegíacas, ora marcada por contornos messiânicos, bíblicos, míticos, ora equacionada como a celebração de um rito iniciático, ora encarada como uma quase representação litúrgica de um passado português com vista à sua salvação, sendo o poeta o "sacerdote" e o ponto de ligação entre Deus e os seus "fieis" leitores —, a Mensagem poderá ser apreciada como um texto de natureza épica em sintonia com os tempos modernos, combinando, portanto, com um tempo por onde uma, desenganada, Modernidade modifica sentidos da história com a "morte de Deus" e com a perceção do progresso ligado à historicidade (ainda que marcadamente concorde com a vontade salvífica na edificação de um mundo novo com base na razão científica e tecnológica). E, judicioso, Pessoa tão bem percebe e notifica o intenso desassossego que configura um contexto histórico (o final do século XIX e o início do século XX) que traduz dolorosamente as consequências da falência positivista e a desintegração do monolitismo ideológico - sendo que, assim considerada, a questão encontra-se indissociável dos contornos teóricos identificáveis com os que Maria Helena Nery Garcez apresenta, quando, apreciando a Mensagem como um «poema épico dos tempos modernos», pergunta: «Poderemos chamar Mensagem de epopeia?»; responde logo de seguida: «Não, se entendermos epopeia segundo a caracterização da poética clássica. Sim, se entendermos que a poética de uma epopeia do século $\mathrm{XX}$ tem de revelar uma mundividência do século $\mathrm{XX}$ » (GARCEZ, M. H. N., 1995: 161).

\section{O jogo dialogal entre o desalento e a esperança}

É certo, por um lado, que o texto pessoano é um texto de glorificação (da grandeza de Portugal) e de celebração (da aventura marítima portuguesa), e que, tal como acontece, por exemplo, n'Os Lusíadas, recorre à conformação mítica (evidente na figura do Mostrengo [ou 


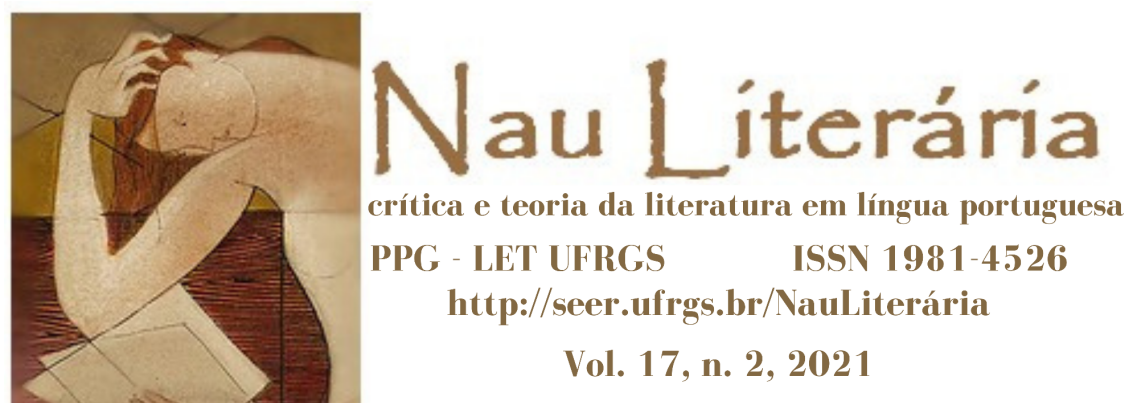

Morcego, como primeiramente apareceu em 1922, no $\mathrm{n}^{\circ} 4$ da revista Contemporânea]) ganhando nos dois textos uma especial operacionalidade o jogo dialogal entre o desalento e a esperança (cf. PRIETO, S., 1995). No texto épico camoniano, encontramos o tom grandiloquente e o elogio da glória do povo português, bem como a questionação da ambição, da vaidade e do orgulho dos portugueses, de uma «Pátria [metida / No gosto da cobiça e na rudeza / Dũa austera, apagada e vil tristeza» (CAMÕES, L. de, 2000: 476 [X, 145]). No texto pessoano, escrito «à beira-mágoa»(O Encoberto.II.Os Avisos/Terceiro. «'Screvo meu livro à beira-mágoa») (FP, 2018: 182)², temos o desalento com a realidade de uma Pátria que perdeu a sua grandeza e se encontra ainda fixada a modelos de um passado épico imobilizador — um pouco à semelhança (no conteúdo, não no modo) da Pátria, de Guerra Junqueiro, que Pessoa habilmente considera superior a'Os Lusíadas ${ }^{3}$.

2 A partir daqui, sempre que, no presente texto, citarmos a Mensagem (PESSOA, Fernando (2018). Edição crítica de Fernando Pessoa - Mensagem e poemas publicados em vida. Edição de Luís Fagundes Duarte. V.I. Lisboa: Imprensa Nacional-Casa da Moeda), recorreremos apenas ao número da página.

3 Repare-se que, na sua obra, Pátria, Junqueiro, referindo-se à decadência de Portugal (devida à atuação da dinastia de Bragança), apresenta este encarnado na personagem de um Doido, «Louco autómato errante, alma cega e funérea, / [...] Mendigo como um cão e mártir como um Cristo» (JUNQUEIRO, G., 1925: 49), «rude herói de outrora», que tivera «o mundo nas mãos» (id: 50), com a idade, segundo o Astrologus, de «oitocentos» anos (id.: 44); e, na parte final, no seu final "Balanço patriótico", Junqueiro vai mais longe, repreendendo de forma mais aguda a decadência de Portugal: "Um povo imbecilizado e resignado» (id.: 129); «Um clero desmoralizado e materialista» (id.: 129); «Uma [...] burguesia, cívica e politicamente corrupta até à medula» (id.: 130); «Um poder legislativo, esfregão de cozinha do executivo» id.: 130); um país com «Instrução miserável» (id.: 132), onde grassa uma «desigualdade revoltante» (id.: 132), um «pessimismo canceroso e corrosivo» (id.: 132-133); um país marcado por uma «crise [...] económica, política ou financeira. [...] nacional» (id.: 133). Como se poderia verificar a renovação da pátria portuguesa, segundo Junqueiro? Com a vinda de um "desejado", de um «justiceiro», de um "crente», o «grande Contestável» Nun'Álvares (id.: 135 ss). A este propósito, é ainda interessante lembrar duas intervenções de Pessoa: por um lado, a resposta ao inquérito "Qual é o mais belo livro português dos últimos trinta anos?" (publicada no jornal República, a 7 de abril de 1914), em que considera a Pátria de Guerra Junqueiro «não só a maior obra dos últimos trinta anos, mas a obra capital do que há até agora de nossa literatura», colocando Os Lusíadas em "segundo lugar» (Pessoa, F., 1986b: 1234); por outro lado, uma carta de (provavelmente) 1916, dirigida a um editor inglês, carta essa na qual afirma também que Junqueiro é «the greatest of all Portuguese Poets (he drove Camões from the first place when he published Pátria in 1896 [...]» (PESSOA, F., 2007: 161). 


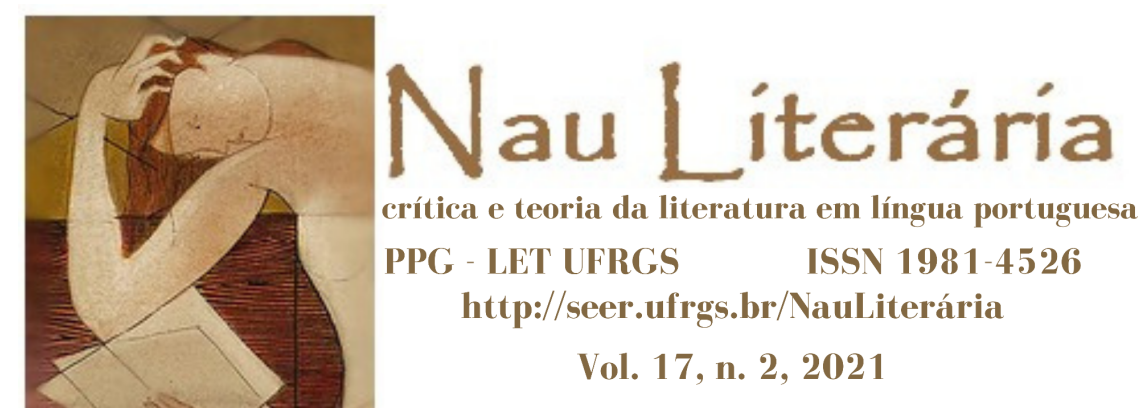

Porém, se, no texto de Camões, transparece a possibilidade de determinar D. Sebastião para a construção de um novo ciclo de feitos heroicos - «E, enquanto eu estes canto - e a vós não posso, / Sublime Rei, que não me atrevo a tanto -, / Tomai as rédeas vós do Reino vosso: / Dareis matéria a nunca ouvido canto. / Comecem a sentir o peso grosso / (Que polo mundo todo faça espanto) / De exércitos e feitos singulares, / De África as terras e do Oriente os mares» (id.: $5[\mathrm{I}, 5])$ 一, no texto de Pessoa, a transição do histórico para o mito permite (também por aí) resgatar o homem português e encontrar uma "Índia nova", que não existe no espaço, mas que empresta um sentido de esperança ao anseio para encontrar aquele «porto sempre por achar» referido em "Padrão", o terceiro poema da segunda parte (Mar Português/III.Padrão) (157). Daí o verso final «É a hora!», do poema "Nevoeiro" (O Encoberto.III.Os Tempos/Quinto.Nevoeiro) (182), quebrando-se, assim, em definitivo, o sentimento de negatividade - apontando essa "Hora" não para um tempo pontual, mas para um processo. Guiando-nos por este prisma, poderá, então, dizer-se que Pessoa, na Mensagem, procura demonstrar que o desígnio português não falhou, incentivando os portugueses (repare-se na fórmula final de despedida epistolar, com uma coloração de bênção apostólica, «Valete, Fratres.»["Passai bem, Irmãos”] [O Encoberto.III.Os Tempos/Quinto.Nevoeiro] [182]) a lançarem-se no cumprimento da sua vocação, resultando do seu empenho a transformação desta mensagem em salvação.

Mais ainda: Pessoa, materializando objetivos de composição messiânica (suprimir a falência dos "tempos modernos", elevando a realidade histórica a um plano mítico e transcendental, permitindo-se, assim, ao sonho e à esperança de aquela se reerguer) e enaltecendo a Pátria portuguesa, pretende resolver a crise estabelecida desde Alcácer-Quibir: intima-nos a conviver com os nossos medos, mas também a ultrapassá-los, transmitindo para isso uma mensagem de fé e de esperança nos destinos de uma nação que considera como predestinada. Nesse sentido, o herói é, já não o "sacerdote" da liturgia do passado, antes a voz da liturgia do futuro; quanto à Pátria representada, essa é a que vive entre a angústia da decadência e a esperança messiânica da redenção. A isso se oferece, portanto, Fernando 


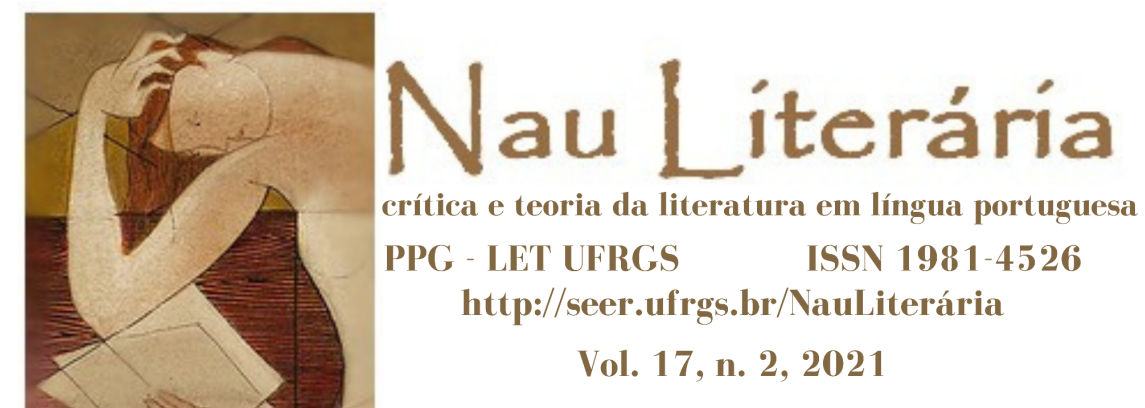

Pessoa: restaurar a verdade-Portugal, obscurecida, contudo, por um "nevoeiro" que, pelas suas particularidades («Tudo é incerto e derradeiro. / Tudo é disperso, nada é inteiro.» ( $O$ Encoberto.III.Os Tempos/Quinto.Nevoeiro) [182]), vai gerando não tanto a presença, efetiva, de Deus, mas a imprevisibilidade, o sonho e o acreditar na efetivação de um Quinto Império e no retorno do "Desejado": o «Desejado virá "encoberto"; [...] chegando, ou chegado, se não perceberá que chegou»(PESSOA, 1986c: 562). E mesmo que, como escreveu no poema “Liberdade”, de 1935, «venha ou não!» (PESSOA, F., 2000: 194), Pessoa acredita na faculdade e na capacidade tão portuguesas de sonhar e de acreditar.

\section{Mensagem e o diferencial épico}

Como quer que seja, é certo que a Mensagem — da qual uma das linhas temáticas nucleares é não o achamento do caminho marítimo para a Índia, mas a figuração desejada do "regresso do Rei” e a eminência do seu retorno - não se mantém imediatamente fiel nem ao cânone clássico da epopeia de Homero e de Virgílio, nem ao modelo épico renascentista.

Como se sabe, o texto de Pessoa, sem cantos, não se complementa com uma Proposição, uma Invocação, uma Dedicatória, uma Narração, uma intervenção tutelar dos deuses (e respetiva conjugação do maravilhoso pagão e maravilhoso cristão) em ação paralela. Mais: reduz a história de Portugal a símbolos. Ao contrário do que acontece, por exemplo, com a epopeia camoniana, não segue a estrutura narrativa do género épico (ainda que todos os poemas, juntos, mesmo de uma forma fragmentária, confiram um sentido narrativo). Para além disso, convoca a polifonia vocal de um "eu" pluralizado em diferentes figuras históricas: Esse "eu" aparece sob a forma ora de um "eu" monologal da figura histórica, ora de um "eu" lírico [aparentemente] distante de tudo, ora de um "eu” enquanto oposição ao "tu”, ora de um "ele", ora de um "nós" identificado com Portugal, ora, até, de um "eu" que se apresenta 1" pessoa do singular, assumindo, contudo o "tu" - como, realmente acontece, n'“As Quinas", terceira secção da primeira parte (143-147), com D. Duarte (Brasão/III.As Quinas/Primeira.D. Duarte, Rei de Portugal), D. Fernando (Brasão/III.As 


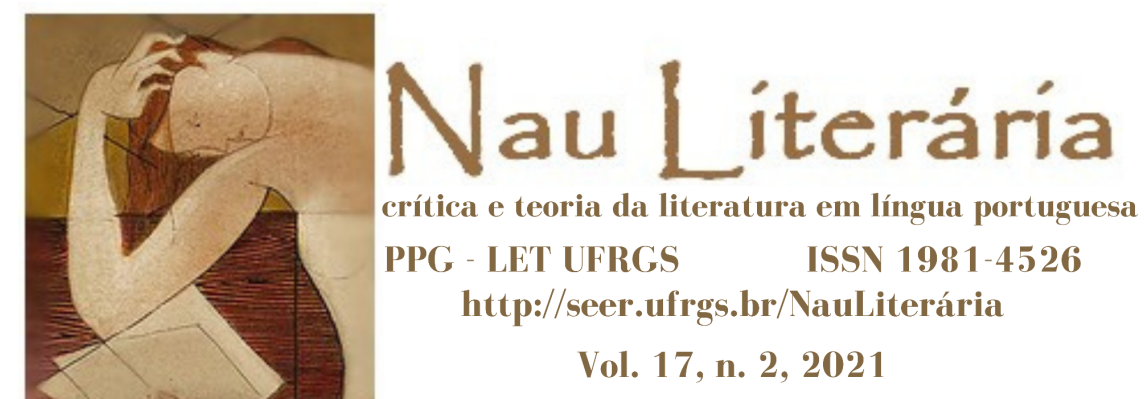

Quinas/Segunda.D. Fernando, Infante de Portugal), D. Pedro (Brasão/III.As Quinas/Terceira.D. Pedro, Regente de Portugal), D. João (Brasão/III.As Quinas/Quarta.D. João, Infante de Portugal) e D. Sebastião (Brasão/III.As Quinas/Quinta.D. Sebastião, Rei de Portugal) (cf. JACOBY, Sissa, 1997: 110 ss).

\section{O propósito ascensional sebastianista}

Além do mais, é indiscutível a presença de todas estas indicações passarem ainda pelo vigor estético-ideológico conferido por Pessoa à divisão triádica do seu texto (número da divindade), que, juntamente com as epígrafes colocadas no início de cada uma das três partes, nos aparece estruturado de modo a que, em fluxo ascensional, percebamos a espiritualidade na história até à unidade final.

Na primeira parte, "Brasão", dividida em 5 secções, e com a epígrafe inicial «Bellum sine bello», o poeta lembra o passado glorioso, com heróis reais e lendários, alertando para o facto de que o "combate" a ser travado pelos portugueses será em terra, sem guerra, espiritual ${ }^{4}$ . Essa ação aparecerá polarizada num Portugal rosto da Europa, protagonista na História Universal, predestinado («com olhar 'sfíngico e fatal») a ser a cabeça do Quinto Império (I.Os Campos/Primeiro.O dos Castelos) (133), numa ação necessariamente conjunta entre o humano e o divino, sem embargo de este se ir apresentando de forma ambivalente, ao “comprar “ "a glória com desgraça» (I.Os Campos/Segundo.O das Quinas) (134) e no papel de oito pilares fundadores da identidade nacional (135-142): o mítico Ulisses (fundador lendário de Lisboa que, "não sendo, existe"); Viriato (que, resistindo à invasão romana, fundou a Lusitânia); o Conde D. Henrique (que, "instrumento" divino, escolhido por Deus [«O herói a si assiste, vário»], fundou um condado); D. Teresa (que, "velando pelos portugueses" esteve na origem da dinastia de Borgonha); D. Afonso Henriques (que, com o dever sagrado que lhe subjaz, fundou a nação portuguesa); D. Dinis (símbolo dos valores espirituais portugueses); D. João I (com quem, mesmo não se encontrando na linha direta de

4 Sobre os significados e simbologias do "Brasão", leia-se CIRURGIÃO, A., 1990: 34 ss. 


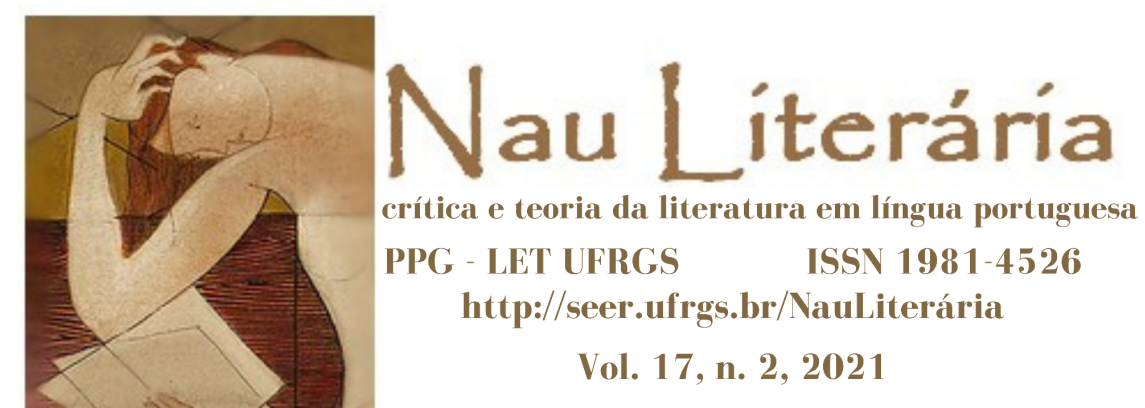

sucessão, acabou por fundar uma dinastia e por conferir a Portugal a «eterna chama» e o espaço sagrado [«(...) Templo / Que Portugal foi feito ser,»]); D. Filipa de Lencastre («Princesa do Santo Graal», confinante com a figura de Nossa Senhora e que esteve na origem da Dinastia de Avis).

De igual modo, a funcionalidade da "guerra sem guerra" é tanto mais significativa quanto maior a atenção conferida a outras cinco figuras da História de Portugal, vítimas (com exceção de D. Pedro) da guerra santa (143-147): o rei D. Duarte (que, animado pelo espírito divino, teve a consciência de ter cumprido [«Inutilmente? Não, porque o cumpri.»]); o Infante D. Fernando (que, ainda que sendo o mais novo da Ínclita Geração, recebeu como o irmão uma missão divina e, Cavaleiro de Cristo, participou em expedições militares no norte de África, com uma forte «febre de Além»); o Regente D. Pedro (que, ainda que incompreendido, viveu sereno [«Calmo sob mudos céus»] perante o silêncio divino e a fortuna contrária [«Não me podia a Sorte dar guarida»]); o Infante D. João (mesmo “diminuído” perante os seus irmãos [«Não fui alguém. Minha alma estava estreita / Entre tão grandes almas minhas pares»]); finalmente, o Rei D. Sebastião, a figura mais privilegiada na Mensagem.

E falar aqui na presença de D. Sebastião na Mensagem é considerá-lo num quadro polifonicamente construído, consequência direta da fortuna concetual e simbólica que historicamente lhe está adscrita, bem como da multiplicidade de avaliações a que foi submetido por Pessoa. Rei mártir, foi o "louco" que sonhou um império sem fronteiras (Brasão/III.As Quinas/Quinta.D. Sebastião, Rei de Portugal), o que morreu em Alcácer-Quibir e o que nos encaminhará para o Quinto Império (Mar Português/XI.A Última Nau). Figura eleita de Deus, encontrou-se com Deus (O Encoberto.I.Os Símbolos/Primeiro.D. Sebastião); ele é o "Desejado", a "Rosa" vital, o "Cristo", que renascerá (O Encoberto.I.Os Símbolos/Segundo.O Quinto Império) e "libertará" pela “espada" (O Encoberto.I.Os Símbolos/Terceiro.O Desejado; O Encoberto.I.Os Símbolos/Quinto.O Encoberto); ele é aquele por quem os portugueses suspiram, na conformação de uma possibilidade, de uma 


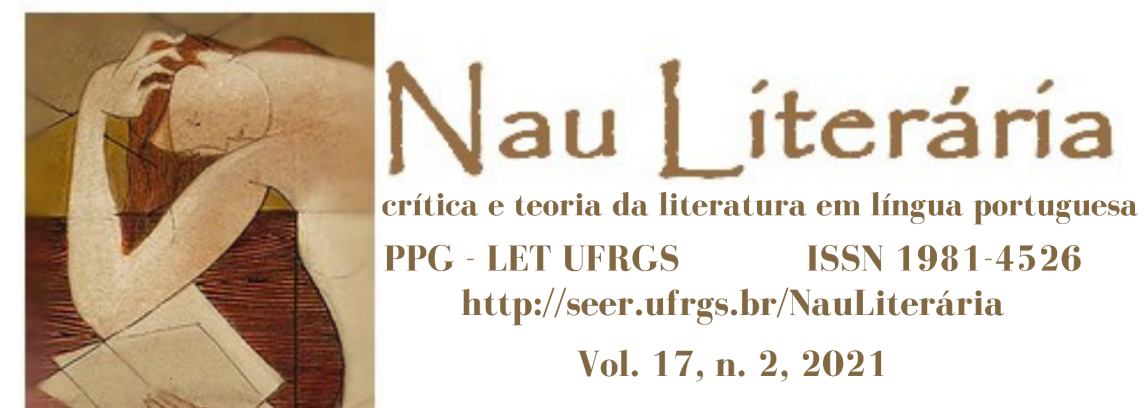

realidade em potência («é luz do etéreo») na qual devemos todos acreditar (O Encoberto.II.Os Avisos/Segundo.António Vieira). Rei algures «desterrado / Em sua vida encantada» (O Encoberto.III.Os Tempos/Terceiro.Calma), virá «Rei» feito Cristo (O Encoberto.II.Os Avisos/Terceiro. "Screvo meu livro à beira-mágoa”); é aquele que, num «Portugal a entristecer», «sem luz», «incerto», «disperso» dará em breve («É a Hora») o sinal para a corporização do Quinto Império - essa nova Ordem de natureza espiritual e mística, esse reino espiritual fora do espaço e do tempo que, produto de uma vontade divina e de um fazer humano, se encontra profundamente ligado a um passado de sofrimento, choros, ausências e perdas.

\section{Mensagem e a elaboração do sentido não positivista}

Sobretudo por isso se justifica, então, dizer que o sofrimento do povo português representado na Mensagem pessoana deve igualmente ser entendido como plataforma para o resgate daquele, entregando-se, então, o poeta à celebração de possibilidades outras que o racionalismo positivista não soube oferecer. E, por essa ótica, encontraremos legitimada a justificação estruturante para o período e os atores da proeza marítima quando acrescentamos as propriedades de sentido que advêm dos exemplos: do luminoso, purificado e mestre Nun'Álvares Pereira (Brasão/IV.A Coroa/Nun'Álvares Pereira); do arquiteto da aventura marítima, D. Henrique, que preside ao destino de todos e impera sobre «o mar novo e as mortas eras» (Brasão/V.O Timbre/A Cabeça do Grifo: O Infante D. Henrique); do futuro rei dos mares e dos céus D. João II (Brasão/V.O Timbre/Uma Asa do Grifo: D. João, o Segundo); do «poderoso» Afonso de Albuquerque (Brasão/V.O Timbre/A outra Asa do Grifo: Afonso de Albuquerque) (148-151).

Essa proeza comparece de forma ainda mais evidente na segunda parte do texto pessoano, "Mar Português", certeiramente apresentada com a epígrafe com que é apresentada: precisamente, «Possessio maris» - epígrafe que consente por inteiro a vigência da esfera marítima. Aí, concede Pessoa a voz, por um lado, aos heróis individuais: o "português 


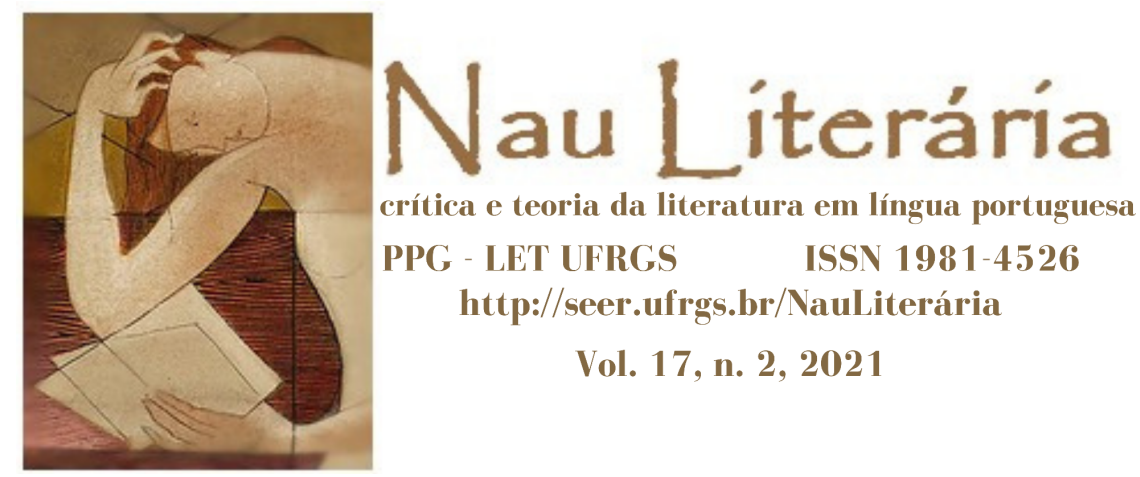

sagrado" e executor Infante D. Henrique, o tenaz homem do leme Bartolomeu Dias, o sempre presente Fernão de Magalhães, o merecido «Argonauta» Vasco da Gama; por outro, aos heróis coletivos, os «Colombos» - animados, contudo, pelos portugueses "Descobridores do Ocidente", timoneiros das navegações além-mar que, com tenacidade, venceram os obstáculos do anterior mar de Ulisses e persistiram naqueles que viveram a separação e a perda, o ver partir e o não regressar (155-166). E destes tão-pouco se esquece Pessoa, de igual modo representantes de uma «chama, que a vida em nós criou», a única capaz de fazer renascer a esperança na concreção da $3^{a}$ Dinastia de Portugal que Pessoa singulariza como o Quinto Império - quadro, como se sabe, (pre)anunciado por Bandarra, nos sonhos das suas Trovas, e pelo Padre António Vieira, no seu entendimento da Lux Mundi portuguesa na nova era da Humanidade (assente nos valores de harmonia universal das diferenças), nova era essa anunciada em Esperanças de Portugal, Quinto Império do Mundo, no "Livro Anteprimeiro" da História do Futuro e nas Chaves dos Profetas 5 .

Assim se confirma, portanto, o perfil de alguém para quem o sentido da vivência de um tempo e um espaço possíveis se torna em princípio uma opção capaz de lhe fornecer um determinado sentido de permanência, cingida porém ao reconhecimento dolorosamente sentido de uma decadência nacional, só corrigida, «Paz in excelsis» (epígrafe que marca a $3^{\mathrm{a}}$ parte da Mensagem), com o Desejado, o «Galaaz com pátria», o «Mestre da Paz» (171) não sem, todavia, se considerar que essa decadência deve ser encarada como sinal para a sua

5 A todas estas noções, não é de igual modo indiferente o posicionamento de Pessoa relativamente ao lugar que a Língua Portuguesa tem nesse estado civilizacional último e transcendente, a esse império cultural (logo, linguístico), ao qual Pessoa confere uma essência profundamente espiritual; e, por diversas vezes, acentua o que para si considerava ser obrigatório para que esse império se efetivasse: «Uma língua apta para isso», o «aparecimento de homens de génio literário, escrevendo nessa língua, e ilustrando-a», e uma «base material imperial para se poder expandir (ainda mais) essa língua» (PESSOA, F., 1986c: 725). Nesse sentido, destaca alguns fatores primordiais conformadores daquele estado último: por um lado, a capacidade da língua conferindo Pessoa o protagonismo à língua portuguesa, que considera, ao lado do inglês e do castelhano, uma das cinco "línguas universais" (PESSOA, F., 1993: 234), porque possui «uma grande literatura», tem um grande «número de pessoas que a [...] [fale] naturalmente» (id.: 237); por outro lado, o "imperialismo cultural", percebido como o "império de gramáticos e de poetas" (PESSOA, F., 1986c: 727). 


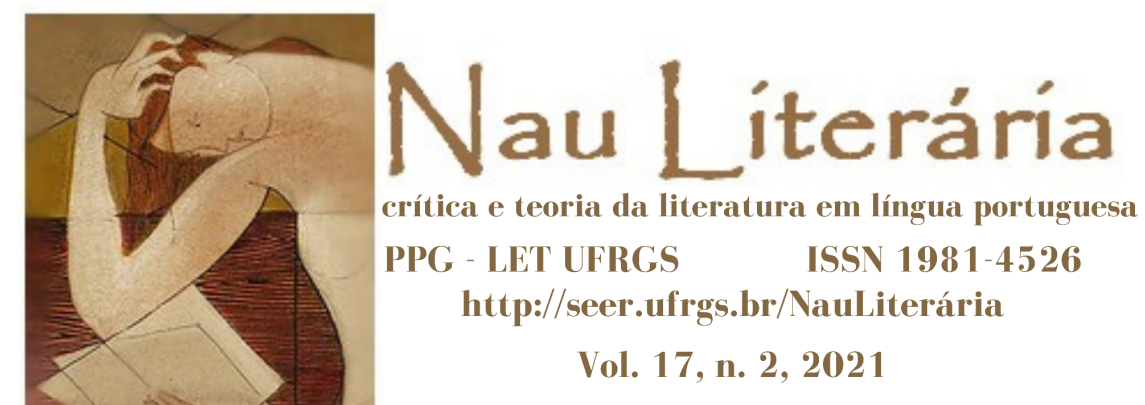

própria superação. E, nesta ordem de pensamento, o mito é um espaço necessário para a reconfiguração do moderno e para a permanência do Ser nacional. Os Lusíadas celebram-no e ao passado. A Mensagem celebra-o, também, e ao futuro - interessando a Pessoa considerar, acima de tudo, Portugal enquanto virtualidade, comparecendo aí o passado em função do futuro; ou, como como doutrina Pessoa numa entrevista concedida a 13 de outubro de 1923 a António Alves Martins na Revista Portuguesa (n ${ }^{\circ}$ s 23/24): «Literariamente, o passado de Portugal está no futuro» (PESSOA, F., 1986c: 702); e conclui: «Há só um período de criação na nossa história literária: não chegou ainda» (id.: 703).

\section{Da abordagem poética do passado ao vigor patriótico nacionalista e} sebastianista

Qualquer que seja o enquadramento sobre as diversas linhas de leitura da Mensagem, teremos que reconhecer que elas se tendem a resolver à custa de um cuidadoso trabalho literário por parte de Pessoa, na forma como os valores semânticos são suscetíveis de remeterem para a abordagem poética de um passado. E é também isso mesmo que Mensagem leva a cabo: uma seleção de factos históricos, marcada naturalmente pela fragmentação, já que qualquer recuperação anamnésica que visa uma significação é limitada. Essa significação, podemos encontrá-la quer nos títulos dos poemas, quer na relação entre os diferentes poemas, quer na combinação entre o registo mítico e o registo histórico (que aparece "representado" [na conceção ingardiana]), quer na própria mitificação da história, quer, ainda, na vinculação de Pessoa a algumas marcas que traduzem a (chamada) épica moderna, como, por exemplo, a delegação de poderes conferida agora não aos velhos deuses, mas a um Deus afastado, bem como a cedência de protagonismo à divinização do homem, que (reflexo mediato de uma afloração patriotista) um certo sebastianismo marcante acaba por intensificar.

Sabe-se que, depois do seu regresso de Durban, Pessoa, decide assumir a sua plena condição de português, mostrando-se norteado por um «intenso sentimento patriótico» e um «intenso desejo de melhorar a situação de Portugal» (como escreve em provavelmente 1908 


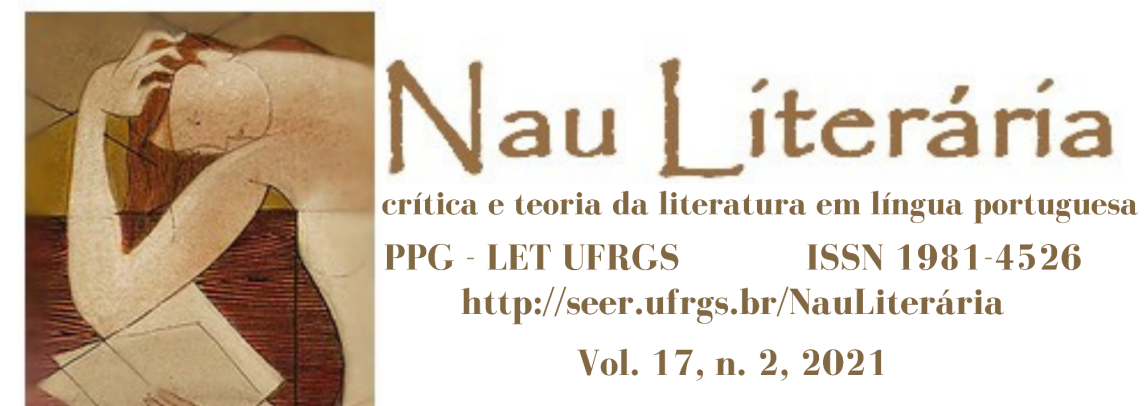

[PESSOA, F., 1986b: 79]); nos artigos de 1912, reafirmará essa anuência, e, em 19 de janeiro de 1915, numa carta dirigida a Armando Côrtes-Rodrigues, acaba mesmo por confessar que lhe "passara" a «ambição grosseira de brilhar por brilhar [...], de querer épater», acrescentando que nele se avolumava «a ideia patriótica» (id.: 177) — ideia decerto «mais intelectual do que afectiva», como ressalta Jacinto do Prado Coelho (COELHO, J. P., 1964: 53). Pode dizer-se, assim, que se vai delineando em Pessoa o perfil de um sujeito onde o fundamento patriótico se torna uma opção capaz de lhe fornecer um determinado sentido de permanência — a si (autodenominado «supra-Camões») e à Comunidade portuguesa («raça dos navegadores e dos criadores de impérios») (LOPES, T. R., 1990: 77).

No âmbito, portanto, de um quadro literário e ideológico muito particular, a representação do Sebastianismo vai assumindo um relevo considerável em Pessoa. Se em 1912, se interessa pela noção de nacionalidade (anotando, inclusivamente, um plano de publicações onde se refere a Bandarra), e, nos artigos sobre "A Nova Poesia Portuguesa", indigita um supra-Camões para a cultura portuguesa, pode dizer-se que esse interesse se amplifica entre 1914 e 1918 - revela-o a carta datada de 8 de setembro de 1914, enviada a Sampaio Bruno, quando se pronuncia sobre a sua inclinação para a «veia messiânica», atraído que se sentia pelo «misterioso [...] fenómeno nacional chamado o Sebastianismo» (PESSOA, F., 1986b: 194). E ainda que, em junho de 1935, mostre notas pessimistas (admitindo poeticamente, na "Elegia na Sombra", que «O Desejado / Talvez não seja mais que um sonho louco» [PESSOA, F., 2000: 204]), o interesse que Pessoa deixa perceber pelo Sebastianismo é extraordinário - apontando, até, curiosamente, o ano de 1888 como o ano da Segunda Vinda de D. Sebastião (PESSOA, F., 1986b: 653).

Considerando-o diversamente como um «movimento religioso, feito em volta duma figura nacional, no sentido dum mito» (PESSOA, F., 1986c: 688), ou como «uma espécie de propaganda com que se pode levantar o moral de uma nação» (id.: 710), ou como «força nacional» (PESSOA, F., 1993: 87), ou como «o único movimento profundamente nacional que tem havido entre nós» (PESSOA, F., 1986c: 654), ou como um «conceito» português (id.: 


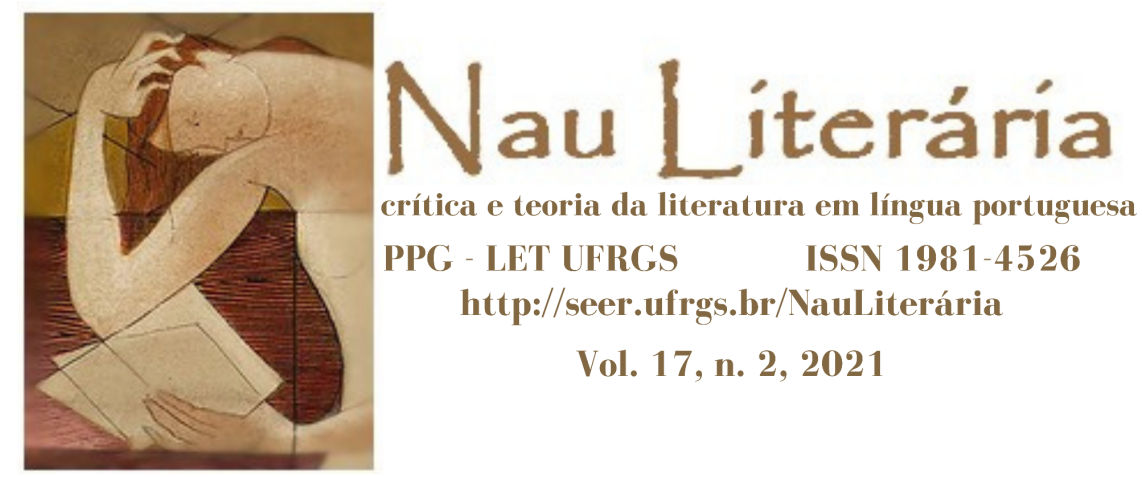

228) com «com raízes profundas no passado e na alma portuguesa» (id.: 710), Pessoa aprecia o mito sebastianista na Mensagem como elemento mobilizador de apelo, regeneração e glorificação para lá do fracasso de Alcácer-Quibir. N'Os Lusíadas, a voz épica não pôde ver nem viver o «Desconcerto do reinado de D. Sebastião» (GARCEZ, M. H. N., 1989b: 92), glorificando Camões os grandes feitos passados até à escrita do seu texto, imprimindo, no entanto, esperança aos grandes feitos que se esperava conseguir com D. Sebastião. Na Mensagem, as desgraças são encaradas como ultrapassáveis, conferindo Pessoa maior interesse à esfera mística do que à histórica e cronológica. Deixa, então, no leitor o reforço do princípio que abre o entendimento do mito sebastianista como um sentimento coletivo e com o retorno daquilo que D. Sebastião simbolizava (como, aliás, o afirmaria numa carta em inglês, a David Davidson, provavelmente depois de 1928 [PESSOA, F., 1996: 120]). Assim arquiteta a relação entre excecionalidade e Sebastianismo. E, a este nível, não podemos esquecer que essa narrativa coletiva encontra na crença do aparecimento de Cristo a Afonso Henriques na batalha de Ourique uma conceção primigénia do povo português como povo eleito e escolhido por Deus para receber aquele que regressará para gerir o império cristão universal (cf. BUESCO, I., 2000: 2016) — questão esta indissociável, como se sabe, da movimentação dialógica das narrativas do ciclo arturiano, das profecias bíblicas, dos antigos escritos atribuídos a Santo Isidoro de Sevilha, onde se vai desenvolvendo esse sentimento coletivo do "rei salvador".

\section{7. "A pessoa do Encoberto"}

São justamente todos estes filões que vão incorporando a narrativa sebastianista, que continuamente se enriquece em múltiplos campos de referência histórica, estórica e literária - problemática essa que tem solicitado múltiplos esforços de conceituação e integrado repertórios e áreas de pensamento com premissas metodológicas e contornos ideológicos de texturas diversas. Nunca nos devemos, contudo, esquecer que, disse-o Pessoa num texto sem 


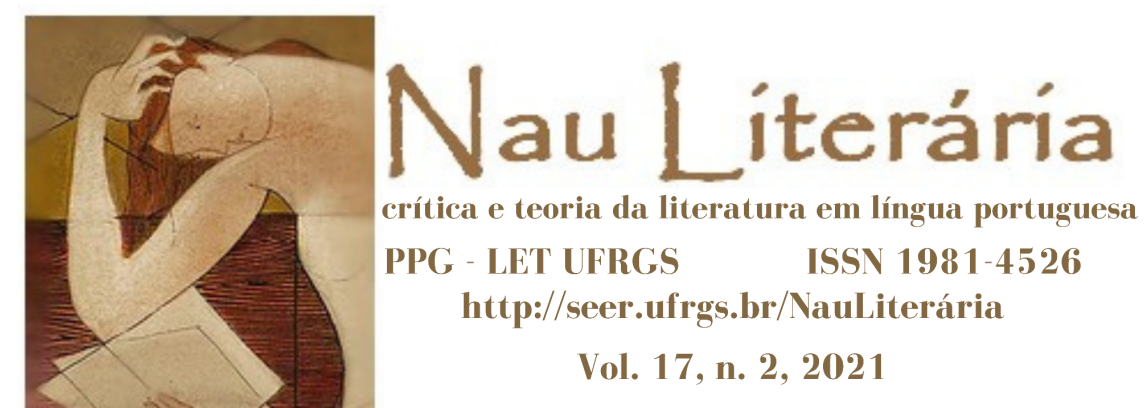

data, uma nação é, sempre, somatoriamente, «uma relação com o passado», «uma relação com o presente» e «uma direcção para o futuro» (PESSOA, F., 1986c: 595).

Nesse sentido, aceitando-se a noção de que a Mensagem se apoia fortemente sobre estas coordenadas, mais facilmente compreenderemos a munificência deste texto pessoano, pelo que estaremos aptos a compreendê-lo e a aceitá-lo enquanto domínio textual onde variavelmente se manifestam, e sempre se manifestarão, múltiplas virtualidades de informação estética. Como quer que seja, acreditamos poderem ser apreendidas aquelas coordenadas como espaços de ativação de uma problemática que se resume ao próprio sujeito português e à necessidade de cada um de nós, portugueses, responder, individualmente, e em conjunto, ao apelo do poeta no poema de 1934 "Vibra, clarim, cuja voz diz", quando invoca: «A todos, todos, feitos num / Que é Portugal, sem lei nem fim, / Convoca, e, erguendo-os um a um, / Vibra, clarim!» (PESSOA, F., 2000: 48). O que quer dizer que, para Fernando Pessoa - tal como também deixa perceber neste poema, onde reitera a visão mística da pátria portuguesa - a mais-valia da narrativa sebastianista, de feição quinto-imperial, encontra-se visceralmente ligada ao valor e à intensidade com que cada um de nós, portugues, quiser nela acreditar. Quando tal acontece, tende-se irreversivelmente para o equacionamento da superlatividade daquela narrativa, confirmando-se por essa ótica toda a sua plenitude, uma plenitude cujos contornos se encontrarão, antes de tudo, no próprio sujeito. Dito de outro modo: querer auferir, esteticamente, literariamente, filosoficamente, historicamente, miticamente, misticamente, as lições da Mensagem não pode nunca deixar de primordialmente pressupor a atitude de cada um de nós, leitores, face a essa experiência. E se, de entre todos os textos conhecidos de Pessoa, fosse preciso encontrar uma passagem que nos ajudasse a melhor compreender esta problemática, que Eduardo Lourenço considerou «o máximo de coincidência com o nosso ser profundo» (LOURENÇO, E., 1978: 24), uma passagem de um texto não datado de Pessoa, encimado pela indicação Bandarra, preencheria com legitimidade tal exigência.

O Encoberto [...] é um conceito nosso; para que venha, é preciso que o façamos aparecer, que o criemos em nós através de nós. 


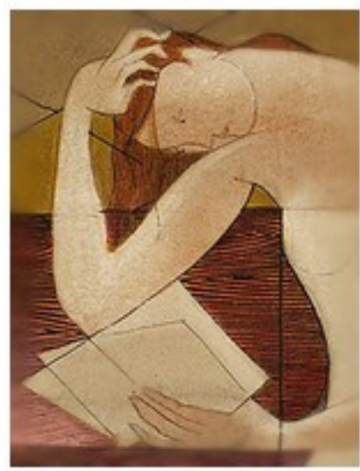

crítica e teoria da literatura em língua portuguesa

PPG - LET UFRGS

ISSN 1981-4526

http://seer.ufrgs.br/NauLiterária

Vol. 17, n. 2, 2021

[...] Deve cada um de nós fazer por em si realizar o máximo que pode de semelhante ao Desejado. A soma, a confluência, a síntese por assim dizer carnal dessas ânsias será a pessoa do Encoberto (PESSOA, F., 1993: 228).

Em conclusão, e refluindo o intuito inicialmente proposto, poderá ser também para este sentido que nos convida a mensagem da Mensagem de Fernando Pessoa, um sentido configurado na (e pela) individualidade de cada português, na (e pela) pujança creditada por cada português no valor exemplar das suas figuras nacionais, no (e pelo) entusiasmo (no seu sentido etimológico) com que cada português se investe para que a possibilidade pessoana possa ser entendida, enfim, como realidade. 


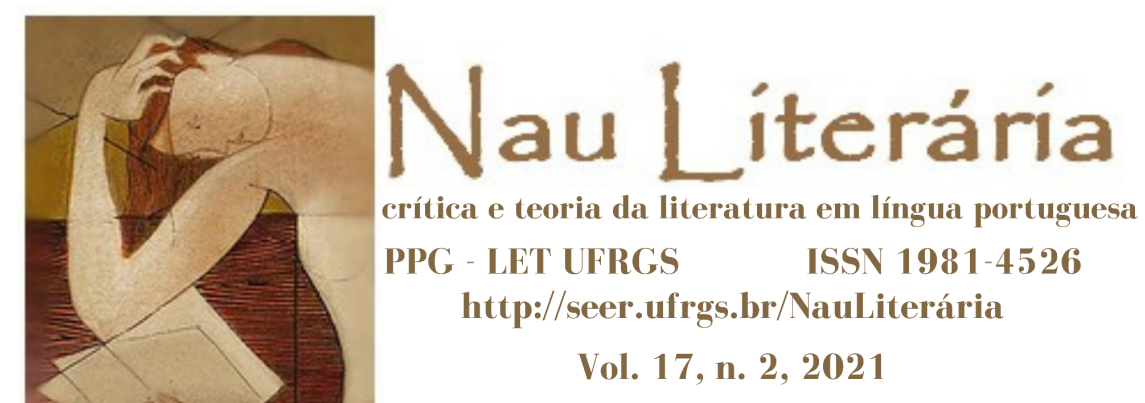

\section{BIBLIOGRAFIA}

\section{BILIOGRAFIA ATIVA}

PESSOA, Fernando (2018). Edição crítica de Fernando Pessoa - Mensagem e poemas publicados em vida. Edição de Luís Fagundes Duarte. V.I. Lisboa: Imprensa Nacional-Casa da Moeda.

\section{BILIOGRAFIA PASSIVA}

ALMEIDA, Onésimo Teotónio (2014). Pessoa, Portugal e o Futuro, Lisboa, Gradiva.

BELCHIOR, Maria de Lourdes (1981). Fernando Pessoa e Luís de Camões: Heróis e Mitos n'Os Lusíadas e na Mensagem. Persona, 5, Abril, pp.3-8.

BERARDINELLI, Cleonice (1973). Uma leitura do Adamastor. In: Estudos Camonianos (31-40). RJ: MEC.

BERARDINELLI, Cleonice (2004). Fernando Pessoa: outra vez te revejo. Rio de Janeiro: Lacerda Editor.

BUESCO, Isabel (2000). Memória e Poder - ensaios de história cultural (séculos XV XVIII). Lisboa: Edição Cosmos.

CAMÕES, Luís de (2000). Os Lusíadas. Prefácio de Álvaro Júlio da Costa Pimpão. Apresentação de Aníbal Pinto de Castro. $4^{\mathrm{a}}$ ed. Lisboa: Instituto Camões.

CIRURGIÃO, António (1990). O “olhar esfingico" da Mensagem de Pessoa. Lisboa: Instituto de Cultura e Língua Portuguesa.

COELHO, Jacinto do Prado (1964). O nacionalismo utópico de Fernando Pessoa. Colóquio Artes e Letras, N.31, Dezembro, pp.53-57.

COELHO, Jacinto do Prado (1983). Camões e Pessoa, Poetas da Utopia. Lisboa: Publicações Europa-América.

CUADRADO FERNÁNDEZ, Perfecto (2015). Fernando Pessoa y la épica de la modernidad. Signa: Revista de la Asociación Española de Semiótica, 24, pp.281-292.

FIGUEIREDO, Fidelino de (1950). A épica portuguesa no século XVI. Lisboa: Imprensa Nacional-Casa da Moeda.

FRANCO, José Eduardo (2009). Vieira e a possibilidade de um Mundo Novo: Quinto Império como projecto de cidadania do futuro. Religião e Ofensa (Novo Formato), 9 de julho, pp.101-114. 


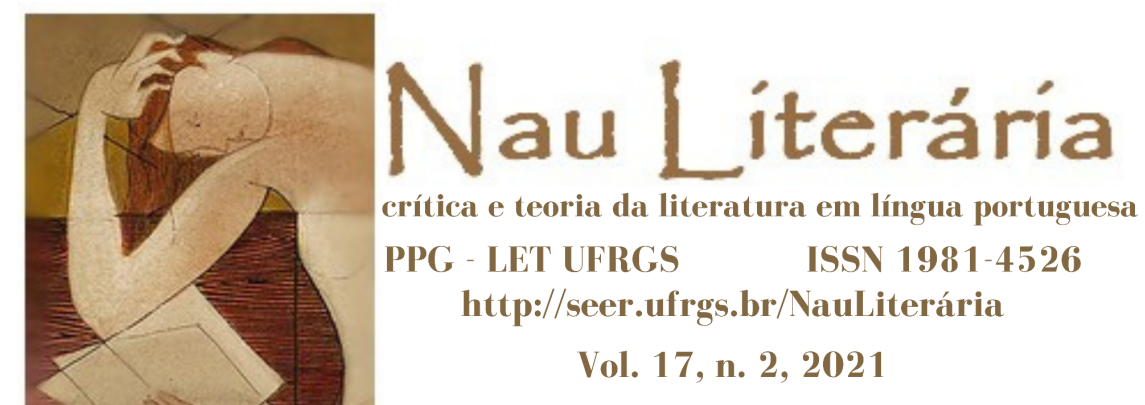

FRANCO, José Eduardo (2010). Profetismo e a ideia de nação: modelação religiosa do destino de um povo. Religare. V.7, N.2, pp. 150-163.

FREITAS, Zilda de Oliveira (2016). A Mensagem de Fernando Pessoa ao povo português. In Dionísio Vila Maior; Annabela Rita [Orgs.], 100 Orpheu (273-287). Lisboa: Edições Esgotadas.

GAGLIARDI, Caio (2014). Mário Beirão e Fernando Pessoa: Lusitânia intertexto de Mensagem. Pessoa Plural. 5 (P./Spring), pp.71-87.

GALHOZ, Maria Aliete (1989). Breve nota atinente ao tema "para uma leitura da 'Mensagem' de Fernando Pessoa. In: AA.VV., Fernando Pessoa: Retrato-Memória (117-121). Lisboa: Faculdade de Filosofia.

GARCEZ, Maria Helena Nery (1989). Do Desconcerto e do Concerto do Mundo em Mensagem. In: Trilhas em Fernando Pessoa e Mário de Sá-Carneiro: coletâneas de artigos e ensaios (89-107). São Paulo: EdUSP.

GARCEZ, Maria Helena Nery (1995). Mensagem: profissão de fé poética. Estudos Portugueses e Africanos, 25/26, pp.159-169.

JACOBY, Sissa (1997). Mensagem. Ficções míticas e históricas do eu-lírico em Fernando Pessoa. Letras de Hoje, V.32, N.2, junho, pp.107-116.

JAKOBSON, Roman (1995). Linguística e Comunicação, 15 a ed. São Paulo: Cultrix.

JUNQUEIRO, Guerra (1925). Pátria. Edição especial. Porto: Lello \& Irmão.

KOHKLOVA, Irene (1995). Pessoa e Camões (Sobre a concepção filosófica de "Mensagem" de F. Pessoa). In: Nós - III Congresso Internacional de Literaturas Lusófonas (299-305), 41-50.

LARSEN, Ingemai (1998). O que faz a alma poder ser de heroe: sobre o conceito de herói na Mensagem de Fernando Pessoa. In: Actas do Quinto Congresso da Associação Internacional de Lusitanistas - Universidade de Oxford, 1 a 8 de Setembro de 1996 (889-893). Tomo II. Oxford / Coimbra: Associação Internacional de Lusitanistas.

LOPES, Teresa Rita (1990). Pessoa por conhecer - Textos para um novo mapa. V.II. Lisboa: Editorial Estampa.

LOURENÇO, Eduardo (1978). O Labirinto da Saudade. Psicanálise Mítica do Destino Português. Lisboa: Publicações D. Quixote.

MANUEL PEDROSA, José (2005). ¿La muerte de la épica? Las metamorfosis de un género literario, entre la modernidad y la posmodernidad. Revista de Poética Medieval, 14, pp.47-94.

MOISÉS, Massaud (1995). Fernando Pessoa e o supra-Camões. In: Cilene da Cunha Pereira; Paulo Roberto Dias Pereira [Orgs.], Miscelânea de Estudos Linguísticos 


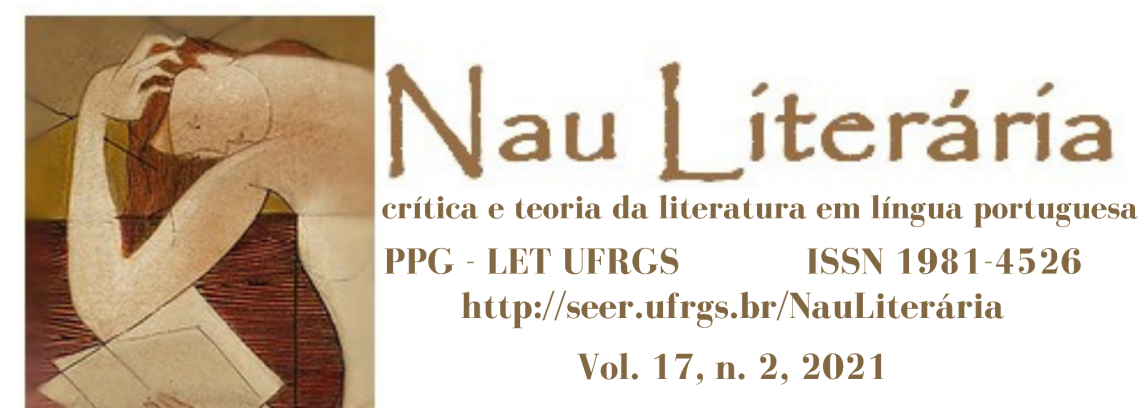

Filológicos e Literários In Memoriam Celso Cunha (843-851). Rio de Janeiro: Editora Nova Fronteira.

MOURÃO-FERREIRA, David (1988). Camões à luz de Pessoa. In: Nos passos de Pessoa (35-47). Lisboa: Ed. Presença.

PESSOA, Fernando (1986a). Obras de Fernando Pessoa. Introduções, organização, biobibliografia e notas de António Quadros. V.I. Porto: Lello \& Irmão Editores.

PESSOA, Fernando (1986b). Obras de Fernando Pessoa. Introduções, organização, biobibliografia e notas de António Quadros. V.II. Porto: Lello \& Irmão Editores.

PESSOA, Fernando (1986c). Obras de Fernando Pessoa. Introduções, organização, biobibliografia e notas de António Quadros. V.III. Porto: Lello \& Irmão Editores.

PESSOA, Fernando (1993). Pessoa Inédito. Coordenação de Teresa Rita Lopes. Lisboa: Livros Horizonte.

PESSOA, Fernando (1996). Correspondência Inédita. Organização de Manuela Parreira da Silva. Lisboa: Livros Horizonte.

PESSOA, Fernando (2000). Edição crítica de Fernando Pessoa - Poemas de Fernando Pessoa 1934-1935. Edição de Luís Prista. V.I, Tomo V. Lisboa: Imprensa Nacional-Casa da Moeda.

PESSOA, Fernando (2007). Obra Essencial de Fernando Pessoa - Cartas. Edição de Richard Zenith. Lisboa: Assírio \& Alvim.

PRIETO, Sônia (1995). Mensagem e Os Lusíadas: convergências e divergências. Estudos Portugueses, 5, pp.187-198.

QUESADO, José Clécio (2016). Mensagem, de Pessoa: uma epopeia da modernidade. Revista Desassossego, 15, junho, pp.66-71.

ROIG, Adrien (1999). La mer dans Mensagem de Fernando Pessoa». Quadrant, 16, pp.33-43.

SEABRA, José Augusto (1996). O Coração do Texto. Le Coeur du Texte - Novos ensaios pessoanos. Lisboa: Edições Cosmos.

SILVA, Francisco Welson Lima da (2008). A Hora e o Nevoeiro (Discurso épico, Vontade de Potência e Mal-estar da Modernidade no poema Mensagem de Fernando Pessoa). Tese de Doutoramento. Natal: Universidade Federal do Rio Grande do Norte.

URIBE, José; SEPÚLVEDA, Pedro (2012). Sebastianismo e Quinto Império: o nacionalismo pessoano À luz de um novo corpus. Pessoa Plural. 1 (P./Spring), pp.139-162.

VECCHIO, Daniel (2016). Na "Madrugada irreal do Quinto Império": da história profética em Mensagem de Fernando Pessoa. Revista Desassossego, 15, junho, pp.72-88. 


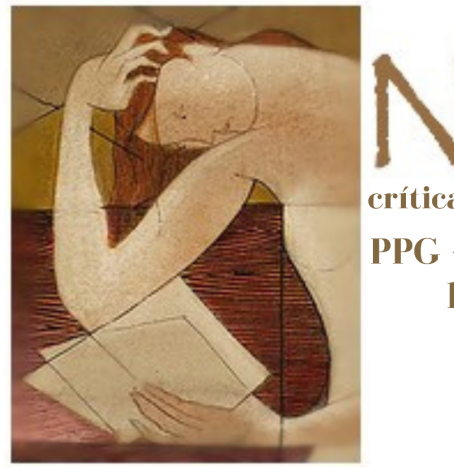

\section{PPG - LET UFRGS \\ ISSN 1981-4526}

http://seer.ufrgs.br/NauLiterária

Vol. 17, n. 2, 2021

VIEIRA, Yara Frateschi (1994). "O monstrengo", poema da transmutação. Revista Camoniana, $2^{\mathrm{a}}$ Série, V.9, pp.117-135. 